University of Texas-Houston Health Science Center, Environmental Health and Safety and School of Public Health R J Emery

University of Texas-Houston Health Science Center, School of Public Health S P Cooper

Correspondence to: Dr R J Emery, University of Texas-Houston Health Science Center,

Environmental Health and Safety, PO Box 20036 Houston, Texas 77225, USA.

\title{
Prudent management of minors with occupational exposures to hazardous agents: the radiation protection "standard of care"
}

\author{
Robert J Emery, Sharon P Cooper
}

For adolescents under the age of 18 , holding a job is a beneficial experience, not only for the income, but also for the discipline, education, and skills acquired. ${ }^{1}$ although no accurate statistics are available that describe the actual numbers of adolescent workers, the US Bureau of Labor Statistics estimated that at least 4 million minors were legally registered as employees in the country in $1988 .^{2}$ This number was acknowledged to be a significant underestimation of the actual number of working minors because the data did not consider agricultural work, nor the common practice of employing minors without official reporting to avoid payment of taxes. Minors hold jobs in virtually every major sector of the economy, with retail trade, service industries, manufacturing, agriculture, and construction being the settings most often involved.' The potential health and safety hazards associated with these work settings range from operating motor vehicles or powered equipment, to exposures to toxic chemicals, potentially infectious agents, or sources of radiation. Nearly 70 deaths and an estimated 37405 job related injuries requiring emergency room treatment affected working adolescents 14 through 17 years of age in the US in $1993 .^{3}$ These unfortunate events are thought to be caused by lack of experience or maturity, inadequate training, or inappropriately designed safety equipment. ${ }^{145}$

Opportunities for the induction of illnesses in working minors also exist, and, given the physiological and psychological differences between this population and adults, the risks associated with occupational exposures to toxic substances is likely to be heightened. Unfortunately, reliable data on the health effects of occupational exposures among minors are not currently available. ${ }^{6}$ So, in recognition of these special risks, safety professionals should consider the implementation of a set of formal practices for the protection of working minors. The parents of working minors should inquire about the availability of such measures when considering the overall benefits of a job for their children. Prudent protection practices might include parental consent, customized safety training, voluntary reductions in exposure levels, and increased worksite safety surveillance. The radiation protection profession has made some initial progress in this regard and this work can be used as the basis upon which a more comprehensive program could be developed.

\section{History of health and safety among working minors}

At the turn of the century, persons under the age of 18 worked in almost every major industry in the US without the benefit of even basic health and safety protection. As public awareness of these deplorable working conditions grew, a series of state child labor laws were enacted, but this legislation addressed only age limits and work hours. After a series of setbacks, the Fair Labor Standards Act (FLSA) was passed in 1938 and raised the full time working age to 16 and strictly limited the working conditions for 14 and 15 year olds. The act also prohibited minors from working in certain hazardous occupations, such a mining, manufacturing explosives, or working with radium. By the 1940s the FLSA was thought to have successfully controlled the problems associated with child labor. But problems persisted, especially among migrant and immigrant minors, as labor problems associated with these populations are traditionally unreported. ${ }^{8}$

Many of the perils to minors noted at the turn of the century still exist today, combined with a number of newly identified health concerns. Minors still work in the agricultural and manufacturing sectors, with the migrant sector of this population being at high risk. ${ }^{9}$ The fastest growing area of the US economy is the service sector, one of the largest employers of youth. A review of nearly 800 teen workers' compensation claims in Connecticut in 1989 showed that $35 \%$ were due to lacerations, of which more than one third stemmed from a single common device, the case cutter. ${ }^{10}$ The case cutter is a knife used to cut open boxes and cartons found in many work settings. The review demonstrated the value of surveillance for the creation and implementation of sound public health interventions. ${ }^{11}$

Illegal employment of minors also increases risks. When an investigation was performed for 
recognized work related fatalities throughout the US for the period $1984-87,41 \%$ of the acts being conducted by these minors were specifically prohibited by the FLSA. ${ }^{12}$ The most common violation noted was the operation of motor vehicles.

\section{Difference between minors and adults}

A variety of factors have been shown to affect an individual's susceptibility to environmental toxicants, including genetic composition, nutrition, personal habits, and age at the time of exposure. Age at exposure affects the eventual biological dose because many toxicokinetic properties such as absorption, metabolism, distribution, and target organ susceptibility, vary with age. Adolescents experience endocrine changes that result in rising levels of sex steroid hormones such as estrogen, progestin, testosterone, and adrenal androgens. ${ }^{13}$ Physical growth changes are also rapid in adolescents as height growth velocity and weight velocity increases and then peaks. ${ }^{14}$ Each of these physiological differences may influence the responses to exposure to toxins exhibited by minors compared with adults.

A working minor's exposure can also be modified by psychological factors. Adolescents have been repeatedly shown to be more prone than adults to engage in risk taking behaviors. ${ }^{15}$ These actions are combined with a reduced understanding or concern for immediate or long term consequences. ${ }^{16}$

The increased opportunity for manifestation of exposure response also plays an important part in the differentiation of concerns between minors and adults. For agents exhibiting known latency periods before the manifestation of a biological response, such as benzene and leukemia, exposures at earlier ages hold a greater potential for impacting on an individual's life span compared with those received later in life. ${ }^{17}$

A general lack of information on the biological responses of minors to exposures to toxic substances has been repeatedly noted. And with occupational exposure limits and recommendations being based on data almost exclusively from adult males, unequivocal reliance on such limits as satisfactory for minors may not be appropriate.

\section{Radiation protection model}

Within 10 years of the discovery of radioactivity by Henri Becquerel in 1896, Bergonie and Tribondeau postulated that the relative radiosensitivity of mammalian cells was influenced by their present and future rate of cell division and their specialization. ${ }^{18}$ This hypothesis was repeatedly verified through experimentation and became the rationale for the establishment of reduced dose limits for individuals under 18 years of age due to the rapid biological development that occurs before adulthood.

In 1964 and 1966, the National Council on Radiation Protection and Measurements recommended that persons under 18 years of age "shall not be occupationally exposed to radiation". ${ }^{19}{ }^{20}$ The council suggested a provision for educational activities, recommending that individuals not receive "an exposure exceeding 1 milliSievert ( $1 \mathrm{mSv}$ or $0.1 \mathrm{rem})$ per year due to their educational activities". This level is $2 \%$ of the adult annual occupational exposure limit of $50 \mathrm{mSv}$ ( $5 \mathrm{rem})$. For comparison, the average dose to members of the US population due to background sources of radiation is approximately $3 \mathrm{mSv}(0.3 \mathrm{rem})$ per year.

The US Nuclear Regulatory Commission (US NRC) promulgates radiation protection regulations for commercial nuclear power plants and users of by-product radioactive materials on a national level. It considers the recommendations of the National Council on Radiation Protection and Measurements and other organizations when drafting rules. Interestingly, the US NRC rules allow for occupational radiation doses to minors up to " $10 \%$ of the annual dose limits specified for adult workers" (or $5 \mathrm{mSv}$ (0.5 rem) per year). ${ }^{7}$ The US NRC rules also uniquely require that occupational exposures be maintained "as low as reasonably achievable" (ALARA). ${ }^{21}$ ALARA is a conservative approach to managing radiation exposures based on an assumed linear nothreshold dose response model. The ALARA approach to radiation protection assumes that any increase in exposure results in a corresponding increase in risk, although a significant body of scientific knowledge exists to suggest that some form of a threshold of increased risk does indeed exist. ${ }^{22}$ Inherent in the ALARA regulatory requirement is the development of a formal "radiation protection program" which must justify exposures not considered to be "reasonable".

The radiation protection community has also established a specific dose limit for the fetus when a pregnant mother is employed. The cumulative occupational dose to the fetus for the entire gestational period may not exceed $5 \mathrm{mSv}(0.5 \mathrm{rem})$.

Radiation protection appears to be the only health and safety profession that has formally acknowledged the need for special (that is lower) occupational exposure safeguards for working minors. But workplaces can contain a variety of other potential hazards that may represent special risks to adolescents. Examples include formaldehyde vapors in the garment and furniture industries, solvents in painting, pesticides in agriculture and lawn care, and benzene in gasoline service stations. ${ }^{23}$ The information available on the biological effects on such exposures to minors is scant, and repeated calls have been made for more funding for research in this area. ${ }^{6}$ Until such studies are undertaken, minors exposed to toxins such as these represent an uncertain risk to both themselves and their employers.

The national regulatory authority in the US that establishes occupational exposure limits for toxic agents is the Department of Labor's Occupational Safety and Health Administration (OSHA). The occupational exposure limits for toxic substances promulgated by OSHA, termed permissible exposure limits or PELs, 
are applicable to all employees. ${ }^{24}$ Although a part of the OSHA regulations are dedicated to "occupations particularly hazardous for the employment of minors between 16 and 18 years of age, or detrimental to their health or well-being", there is a lack of guidance on reductions of exposure limits other than those listed for radiation. ${ }^{25}$ The preponderance of the regulation addresses work prohibitions for minors and is dedicated to heavy industries such as mining, milling, and explosives.

One of the most widely recognized professional organizations publishing suggested occupational exposure limits is the American Conference of Governmental Industrial Hygienists (ACGIH). Their suggested limits, contained in the threshold limit values (TLV) for chemical substances and physical agents and biological exposure indices are reviewed and updated on schedules that far outpace the reviews and updates accomplished by OSHA. ${ }^{26}$ The TLV guides do not describe or suggest occupational limits for exposures to minors but do acknowledge that “... a small percentage of workers may experience discomfort from some substances at concentrations at or below the [recommended] threshold limit; a smaller percentage may be affected more seriously by aggravation of a pre-existing condition or by development of an occupational illness". The ACGIH further states that "in spite of the fact that serious injury is not believed likely as a result of exposure to the threshold limit concentrations, the best practice is to maintain concentrations of all atmospheric contaminants as low as is practical" ${ }^{26} \mathrm{~A}$ similar review of available compilations of international occupational exposure guidelines did not reveal any special limits for working minors as well. ${ }^{27}$

The existence of the radiation protection model program for reducing occupational exposures to minors, combined with the general limitations and prohibitions of the FLSA, OSHA, and ACGIH guidelines for occupational exposures, establish a situation that can arguably be considered a "standard of care" for working minors. Under US law, the standard of care is defined as "that degree of care which a reasonably prudent person should exercise under [the] same or similar circumstances". ${ }^{28}$ With an understanding of the basis for the radiation protection model and the limitations of other occupational exposure limits, safety professionals can implement a set of prudent practices that should serve to protect both the employed minor and the employer.

\section{Suggested prudent practices}

Employees and parents are faced with a difficult dilemma when confronted with the issue of adequately protecting working minors. A balance must be achieved between the benefits available to the youth through pay and experience versus the potential risks to both the individual and the organization. In the absence of any national regulatory guidance, perhaps the best alternative is the establishment of prudent practices such as those described below:

(1) OBTAIN INFORMED PARENTAL CONSENT

The creation of a document that describes the work setting, possible exposures and durations, along with any associated risks to be signed by a parent or guardian.

(2) PROVIDE FORMALIZED SAFETY TRAINING

The completion of safety training provided at a level of understanding for the minor and the creation of documentation system to record such activities. When practical, an invitation can be extended to the parents or guardians to participate in the training to further enhance the efforts of employers to fully disclose possible workplace hazards and the protections and safeguards in place.

\section{(3) EMPHASIZE THE EDUCATIONAL BENEFITS OF} THE JOB

Employers recruiting minor workers may wish to enter into formal agreements with vocational training programs that could enhance the educational value of the jobs.

(4) VOLUNTARILY REDUCE EXPOSURE LEVELS Health and safety professionals can ensure that engineering controls, work practices and procedures are utilized to their fullest extent to reduce exposure levels to at least some level below the established PEL or TLV. Reduction to levels as low as practicable would be preferable.

(5) CONDUCT REGULAR WORKPLACE REVIEWS AND EXPOSURE MONITORING

The completion of documented workplace safety reviews would demonstrate an employer's commitment to maintaining a minor's workplace in a safe and healthy condition, and actual personnel monitoring data could be accumulated to support workplace reviews.

\section{(6) CLEARLY ASSIGN WORK DUTIES AND} RESPONSIBILITIES

Working minors should be provided with a job description that clearly describes the tasks to be performed. The description should also explicitly identify the position's supervisor. The supervisor of the minor worker should be assigned the primary responsibility of ensuring that the individual is maintained in a safe and healthy environment.

A formal program modeled after the tenets described above has been designed and implemented at the University of Texas-Houston Health Science Center, where advanced placement high school students regularly work in laboratories containing a variety of potential hazards. A formalized worksite safety review is conducted before the arrival of a working minor, which is initiated by the submittal of written request signed by the worker's supervisor and the parent or legal guardian. Upon completion of the safety review, the request is also signed by the safety office. Customized safety training is provided to the minor upon entry into the workplace. Although offers are 
extended to the parents to attend these training sessions, to date, no parents have actually attended, although a few inquiry phone calls from parents have been received. The frequency of routine safety surveillance activities is predicated by the level of risk associated with the work, and usually consists of semiannual or quarterly facility reviews. When the possibility of exposures to chemical agents or radiation sources is present, efforts are made to reduce exposures to levels that are as low as reasonable, and a $10 \%$ reduction from established adult limits is used as a guide. The estimated added cost to provide the level of service has been minimal and can best be estimated in units of added safety staff workload. The Environmental Health and Safety Department presently consists of 17 full time equivalent (FTE) technical staff and it is estimated that to accommodate the approximately 100-150 minors who enter our workplace each year, an additional 0.25 FTE annual workload has been added.

In summary, specific exposure limits established for many hazards in the workplace are based on adult physiologic models and may not sufficiently protect young workers. The continuity of radiation protection in the workplace from the prenatal period to age 18 years could serve as a prototype for programs to address other potentially hazardous agents whose risks may be enhanced with childhood exposures.

1 Children's Safety Network at Education Development Center and Massachusetts Occupational Health Surveilance Program. Protecting working teens: a public health resource guide. Newton, MA: Children's Safety Network at Education Development, 1995.

2 Landrigan PJ. Child labor: a re-emerging threat. Am $\mathcal{F}$ Ind Med 1993;24:267-8.

3 Layne LA, Castillo DN, Stout N, et al. Adolescent occupational injuries requiring hospital emergency department treatment: a nationally representative sample. Am $\mathcal{F}$ Public Health 1994;84:657-60.

4 Ehlers JK, Connon C, Themann CL, et al. Health and safety hazards associated with farming. American Association of hazards associated with farming. American Association

5 Heyer NJ, Franklin G, Rivara FP, et al. Occupational injuries Heyer NJ, Franklin G, Rivara FP, et al. Occupational injuries
among minors doing farm work in Washington state 1986 among minors doing farm work in Washingto
to 1989 . Am $\mathcal{~ P ~ P u b l i c ~ H e a l t h ~ 1 9 9 2 ; 8 2 : 5 5 7 - 6 0 . ~}$

6 Carlson JE, Sokoloff K. Preventing child exposures to environmental hazards: research and policy issues. Environ Health Perspect 1995;103(suppl 6):3-5.
7 US Nuclear Regulatory Commission. Code of federal regulations, title 10, part 20.1207. Occupational dose limits for minors. Washington, DC: US NRC, 1993.

8 Postol T. Public health and working children in twentiethcentury America: an historical overview. 7 Public Health Policy 1993:348-53 Autumn.

9 Rosner D. Youth, race, and labor: working kids and histori$\mathrm{cal}$ ambivalence in twentieth century America. Am $\mathcal{F}$ Ind Med 1993;24:275-81.

10 Banco L, Lapidus G, Braddock M. Work-related injury among Connecticut minors. Pediatrics 1992;89:957-60.

11 Banco L, Lapidus G, Monopili J, et al. The safe teen work project: a study to reduce cutting injuries among young and inexperienced workers. Am f Ind Med 1997;31:619-22.

12 Saruda A, Halperin W. Work related deaths m children. $A m$ f Ind Med 1991;19:739 45 .

13 Bearer CF. How are children different from adults? Environ Health Perspect 1995;103(suppl 6):7-12.

14 Neinstein LS, Kaufman F. Normal physical growth and development. In: Neinstein LS, ed. Adolescent health care: a practical guide. 2nd Ed. Baltimore: Urban and Schwarzonberg, 1991: 3-37.

15 Jessor R. Risk behavior in adolescence: a psychosocial framework for understanding and action. $f$ Adolesc Health 1991;12:597-605.

16 Irwin CE, Millstien SG. Biopsychosocial correlates of risk-taking behaviors during adolescence: can the physician intervene? F Adolesc Health Care 1986;7:82-96S.

17 Stellman JM, Stellman SD. Cancer and the workplace. $C A$ Cancer f Clin 1996;46:70-92.

18 Gollnick GA. Basic radiation protection technology. 3rd Ed. Altadena, CA: Pacific Radiation Corp, 1994.

19 National Council on Radiation Protection and Measurements. Report number 30: safe handling of radioactive materials. Washington, DC: NCRP, 1964

20 National Council on Radiation Protection and Measurements. Report number 32: radiation protection in educational institutions. Washington, DC: NCRP, 1966.

21 US Nuclear Regulatory Commission. Code of federal regulations, title 10 , part 20.1101. Radiation protection programs. Washington, DC: US NRC, 1993.

22 Cember H. Introduction to health physics. 3rd Ed. New York: McGraw-Hill, 1996: 274-8.

23 Cooper SP, Rothstein MA. Health hazards among working children in Texas. South Med F 1995;88:550-4.

24 US Department of Labor Occupational Safety and Health Administration. 29 CFR 1910.2. Occupational health and safety standards: definitions. Washington, DC: US Department of Labor Occupational Safety and Health Administration, 1996.

25 US Department of Labor Occupational Safety and Health Administration. 29 CFR chapter V, subpart E. Occupations particularly hazardous for the employment of minors between 16 and 18 years of age or detrimental to their health or well-being. Washington, DC: US Department of Labor Occupational Safety and Health Administration, 1995.

26 ACGIH 1993-1994. Threshold limit values for chemical substances and physical agents and the biological exposures indexes. Cincinnati, OH: American Conference of Governmental Industrial Hygienists, 1993.

27 Cook W. Occupational exposure limits-worldwide. Fairfax, VA: American Industrial Hygiene Association, 1987.

28 Black HC. Black's law dictionary. 5th Ed. St Paul, MN: West Publishing, 1979: 930-1. 